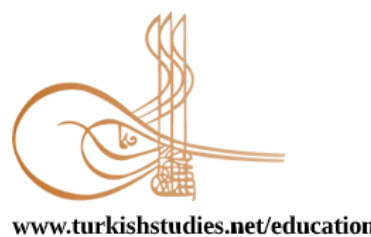

Turkish Studies - Educational Sciences

Research Article / Araștırma Makalesi

\title{
İstasyon Tekniğine Dayalı Yapılan Fen Öğretimi Laboratuvar Uygulamaları II'nin Fen Bilgisi Öğretmen Adaylarının Ders Başarısına Etkisi
}

\author{
The Effect of Station Teaching on the Achievement of Prospective Science \\ Teachers in the Course of Science Teaching Laboratory Practices II
}

\author{
Merve Eker $^{*}$ - Hatice Kurçiçek ${ }^{* *}$ - İbrahim Yüksel ${ }^{* * *}$
}

\begin{abstract}
The aim of this study is to examine the effect of station teaching on the achievement of the prospective science teachers in the Course of Science Teaching Laboratory Practices II. This study was conducted in a quasi-experimental design and it was carried out with 58 third year students studying in the Science Teaching Program of the Faculty of Education of a state university in the spring term of 2018-2019 academic year. Experimental and control groups were formed and station technique activities prepared by the researchers were applied in the experimental group and the instruction based on the confirmatory laboratory approach was applied in the control group. There were 28 students in the experimental group and 30 students in the control group. As the data collection tool, Science Teaching Laboratory Applications Achievement Test (STLAAT), which was developed by Kircicek and Yuksel (2018), was used. Quantitative analysis method was used in the analysis of the data and the data was analysed using the package program of SPSS 22 . There was a statistically significant difference between STLAAT pre and post-test mean scores in favour of post-test in terms of the science laboratory achievements of the students in the course taught with the station technique. There was a statistically significant difference between the achievement pre and post-test mean scores in terms of the science laboratory achievements of the students in the course taught with confirmatory laboratory approach. A statistically significant difference was found between the pre and post-test mean scores in terms of the science laboratory achievements of the students in the course taught with the station technique and the post test mean scores of the students taught with confirmatory laboratory approach.
\end{abstract}

\footnotetext{
${ }^{*}$ Yüksek Lisans Öğrencisi, Gazi Üniversitesi, Gazi Eğitim Bilimleri Enstitüsü, Fen Bilgisi Öğretmenliği Master Degree Student, Gazi University, Gazi Institute of Educational Sciences, Science Teaching Programme ORCID 0000-0002-5938-7954 merveker1@gmail.com

** Doktora Öğrencisi, Gazi Üniversitesi, Gazi Eğitim Bilimleri Enstitüsü, Fen Bilgisi Öğretmenliği PhD Student, Gazi University, Gazi Institute of Educational Sciences, Science Teaching Programme ORCID 0000-0002-6681-7967

htckrccek@gmail.com

**** Dr., Gazi Üniversitesi, Gazi Eğitim Fakültesi, Matematik ve Fen Bilimleri Eğitimi Bölümü, Fen Bilgisi Eğitimi Anabilim Dalı,

PhD., Gazi University, Gazi Faculty of Education, Department of Mathematics and Science Education, Science Education Program

ORCID 0000-0001-5686-9344

ibrahimyuksel@gazi.edu.tr

Cite as/ Atıf: Eker, M. \& Kırçiçek, H. \& Yüksel, İ. (2020). İstasyon tekniğine dayalı yapılan fen öğretimi laboratuvar uygulamaları II'nin fen bilgisi öğretmen adaylarının ders başarısına etkisi, Turkish Studies - Education, 15(3), 17871797. https://dx.doi.org/10.29228/TurkishStudies.37393

Received/Geliş: 21 September/Eylül 2019

Accepted/Kabul: 23 May/Mayis 2020

Checked by plagiarism software

Copyright (C) INTAC LTD, Turkey 
Structured Abstract: The station technique is one of the most important techniques used in the educational environment in order to provide efficient training and qualified skills for the students. , It is likey to say that this technique provides students with similar features such as teaching working together, sharing awareness and controlling what they have learned in person. In the student activity stations, the learning model provides an opportunity for private and cooperative learning activities independently in environments that enable students to actively learn by moving given materials and by providing change in courses (Demir, 2008). The station technique makes a connection between theory and practice. In addition, this technique helps simplify complex content and present it in pieces (Ocak, 2017).

It has a learning that takes individual difference into account for each student. The teachers offer their students the opportunity to prepare activities and equipment by taking into account individual differences with learning stations. It helps students to learn with fun and to realize the different learning abilities that exist in them (Gunes, 2009) and supports learning in science laboratories with fun and together. With the activities prepared according to the individual differences and requirements of the student, the efficiency reaches the highest point.

Confirmatory (deductive or proof) Laboratory Approach is the most commonly used approach in science education by teachers. The laboratory guide or teacher gives detailed information about the subject, preliminary information about the experiment to be conducted, how to conduct the experiment, how to collect the necessary data during and after the experiment, and detailed information about the data collected, compares the experiments with the previous studies and experiments and guides the behaviors of students. The results are often tried to be compared with the expected results. With this feature, this approach allows laboratory courses to take on a special feature such as a cookery book. Thus, students do not need to think freely and to establish a full meaning of the relationship about what they do during the experiment, and they only tend to memorize (Kanl, 2007). In addition, with regard to the views of the students, there are various studies about laboratories pointing out that this approach will not develop skills at students and make the subject boring for the skilful students because they cannot add anything to their individual development (Kayacan, 2014).

The aim of this study is to examine the effect of station teaching on the achievement of Science Teaching Laboratory Practices II course of prospective science teachers. This study was conducted in a quasiexperimental model. The study was carried out with 58 third year students studying in the Science Teaching Program of the Faculty of Education of a state university in the spring term of 2018-2019 academic year. Experimental and control groups were formed and station technique activities prepared by the researchers were applied in the experimental group and the instruction based on the confirmatory laboratory approach was applied in the control group. There were 28 students in the experimental group and 30 students in the control group. In the experimental group where the station technique was applied, examples of the teaching activities based on the station technique in the literature were examined. After obtaining approval from 3 experts in the field of station technique activities, a pilot application was conducted with 10 students one month before the main application. The activities related to the station technique-based teaching and activity materials developed by the researchers were completed in the pilot applications and the main application was started. The main application lasted for 8 weeks.

As the data collection tool Science Teaching Laboratory Applications Achievement Test (STLAAT) which was developed by Kircicek and Yuksel was used (2018). The Cronbach's alpha value of STLAAT's reliability was 0.77 . It is stated that values of 0.7 and above are acceptable (Can, 2018). Validity and reliability calculations of the test were performed by the expert. The average time to complete STLAAT questions was 50 minutes.

It was found that the difference between the mean scores of the students who received the science laboratory pre-test by using the station technique and the ones obtained from the pre-tes of the students $t$ using the confirmatory laboratory approach was not significant. In other words, the experimental group in which the laboratory course was processed with the station technique and the control group using the confirmatory laboratory approach were identical. Depending on the pre and post test mean scores of the science laboratory achievement test of the students using the station technique, it was found that the station technique significantly increased the science laboratory achievement of the students. Kara Ekemen (2017) concluded that station the technique positively affected academic achievement according to the data obtained in his study. Likewise, in their study, Korsacilar and Caliskan (2015) stated that students using the station technique were found to be significantly higher than the achievement test scores of the two groups. According to the achievement test, pre-

Turkish Studies - Education, 15(3) 
test and post-test mean scores of the students who were taught by confirmatory laboratory approach, laboratory activities performed with confirmatory laboratory approach significantly increased the achievement of science laboratory at students. The difference between the post test mean scores of the students who received the laboratory course by using the station technique and the mean scores obtained from the achievement test of the students using the confirmatory laboratory approach was significant in favor of the station technique group. In other words, the science laboratory achievement of the station technique group students increased significantly. The results of this study are limited to the university level. Similar studies can be carried out with secondary school students.

Keywords: Science teacher, station technique, science teaching laboratory applications II, confirmatory laboratory approach, achievement test.

Öz: Bu çalışmanın amacı, istasyon tekniğine dayalı yapılan öğretimin Fen Bilgisi öğretmen adaylarının Fen Öğretimi Laboratuvar Uygulamaları II dersindeki başarısına etkisini incelemektir. Bu çalışma yarı deneysel desende yapılmıştır. Çalışma, 2018-2019 eğitim-öğretim yılı bahar döneminde bir devlet üniversitesinin Eğitim Fakültesi Fen Bilgisi Öğretmenliği Programı’nda öğrenim görmekte olan üçüncü sınıfta okuyan 58 öğrencisi ile gerçekleştirilmiştir. Çalışmada deney ve kontrol grupları oluşturulmuş ve deney grubunda araştırmacılar tarafından hazırlanan istasyon tekniği etkinlikleri, kontrol grubunda ise doğrulayıcı laboratuvar yaklaşımına dayalı öğretim uygulanmıştır. Deney grubunda 28 öğrenci, kontrol grubunda ise 30 öğrenci bulunmaktadır. Veri toplama aracı olarak Kırçiçek ve Yüksel (2018) tarafından geliştirilmiş olan Fen Öğretimi Laboratuvar Uygulamaları Başarı Testi (FÖLUBT) kullanılmıştır. Verilerin analizinde nicel analiz yöntemi kullanılmış ve verilerin analizi SPSS 22 paket programı kullanılarak yapılmıştır. İstasyon tekniği kullanılan öğrencilerin fen laboratuvarı başarıları açısından FÖLUBT ön ve son test ortalamaları arasında son test puanları lehine anlamlı bir farklılık bulunmaktadır. Doğrulayıcı laboratuvar yaklaşımı kullanılarak dersin işlendiği öğrencilerin başarı testi ön test ile son test puan ortalamaları arasında istatistiksel olarak anlamlı bir farklılık bulunmaktadır. İstasyon tekniği kullanılan öğrencilerin fen laboratuvarı başarı testi son test puan ortalaması, doğrulayıcı laboratuvar yaklaşımının kullanıldığı öğrencilerin başarı testinden aldıkları son test puan ortalamalarından istatistiksel olarak anlamlı bir farklılık göstermektedir.

Anahtar Kelimeler: Fen bilgisi öğretmenliği, istasyon tekniği, fen öğretimi laboratuvar uygulamaları II, başarı testi, doğrulayıcı laboratuvar yaklaşımı.

\section{Giriş}

Laboratuvar ortamında öğrencilerin deney yapmalarından, yaparak yaşayarak öğrenme odaklı etkinlikler gerçekleştirmelerinden dolayı laboratuvarlar, fen eğitiminin ayrılmaz bir parçasıdır. Faydalı ve etkili fen öğretiminin gerçekleşebilmesi için laboratuvar uygulamaları zorunludur (Çepni ve Ayvacı, 2006). Ülkemizde eğitim kademelerinde genellikle laboratuvar uygulamalarına yeterli düzeyde önem verilmediği gibi laboratuvar uygulamalarında belirlenen amaçlara yeterli düzeyde ulaşılmadığı düşünülmektedir (Yıldız, 2012).

Laboratuvarda öğrencilere, uygun ve yeterli düzeyde deney çalışmaları için gerekli ortam hazırlanmalıdır. Laboratuvar kullanımında öğretmen ve öğrenci çok önemli etkenlerdir. Laboratuvar kullanımının öğrenciye sağladığı olumlu katkıların ve bu konuda yapılan çalışmaların önemli olduğu anlaşılmaktadır.

Fen laboratuvar uygulamaları iyi yapılandırıldığında öğrencilerin kavram ve kavram çerçeveleri geliştirmelerine olanak sunan öğrenme firsatları sağlayabilir. Bunun yanında öğrencilere araştırmayı, bilimsel düşünme becerileri kazanarak bu düşüncelerini sınıf arkadaşları ve temasda oldukları daha uzman bilim çevreleri ile sınamayı öğrenmek için önemli firsatlar sunmaktadır (Hofstein ve Lunetta, 2004). Yani öğrencilerin bilimsel çalışma disiplinini, anlayışını ve akademik başarısını geliştirebileceği söylenebilir. Öğrenciler bilgilerin altında ezilmez, bilgiye nasıl ulaşacağını bilirler ve böylece bilimsel süreç becerisi kazanırlar (Aktamış ve Ergin 2007). 
Laboratuvar dersleri işlenirken birçok yaklaşım, yöntem ve teknik kullanılabilir. Bunlar arasında istasyon tekniği ve doğrulayıcı laboratuvar yaklaşımı da yer alır.

Öğrencilere verimli eğitim ve nitelikli beceriler kazandırmak için eğitim esnasında yararlanılan en önemli tekniklerden biri de istasyon tekniğidir. Bu teknik ile öğrencilere birlikte çalışmayı öğretme, paylaşma bilinci ve bizzat öğrendiklerini kontrol etme gibi benzer özellikler sağlayacağı söylenebilir. İstasyon tekniğini öğrencilerin hareketli ve verilen malzemelerle aktif öğrenmeyi sağlayacak ortamlarda bağımsız olarak özel ve işbirlikli öğrenme etkinliklerine ortam sağlanır (Demir, 2008). İstasyon tekniği öğrencilerin kendilerine güvenini artırarak, onlarda başarılı olma isteğini geliştirerek grupça çalışmayı öğretmektedir (Zentall ve Zentrall, 1976).

İstasyon tekniği öğrenci ihtiyaçlarını göz önüne aldığı için öğrencilerde başarma isteğini geliştirerek başarılarını artmasını sağlayan bir tekniktir (Furutani, 2007). İstasyon tekniği sayesinde teori ve uygulama arasında bir bağ kurulur. Ayrıca bu teknik, karmaşık olan içeriğin basitleştirilerek parçalar şeklinde sunulmasına yardımcı olur (Ocak, 2017). Her öğrenci için bireysel farklılığı dikkate alan bir öğrenme olmalıdır. Öğrenme istasyonlarıyla öğretmenler bireysel farklılıkları dikkate alarak öğrencilerine etkinlikleri ve araç-gereçleri hazırlama firsatı sunar. Öğrencilerin eğlenerek öğrenmelerine ayrıca kendinde var olan değişik öğrenme kabiliyetlerini fark etmelerine yardımcı olur (Güneş, 2009). Fen laboratuvarları eğlenerek öğrenmeyi destekler. Öğrencinin bireysel farklılıklarına ve gereksinimlerine göre hazırlanan etkinliklerle derste elde edilen verim artacaktır.

Doğrulayıcı (tümdengelim veya ispat) Laboratuvar Yaklaşımı, Kanlı, (2007) ya göre fen bilimleri eğitiminde öğretmenlerin en çok kullandığı yaklaşımdır. Araştırılacak konuyu, yapılacak deneyle ilgili ön bilgiyi, deneyin nasıl gerçekleştirileceğini, deneyin yapıldığ 1 sırada ve sonrasında gerekli olan verilerin nasıl toplanacağını ve toplanan bu veriler hakkında ayrıntılı bilgiyi laboratuvar kılavuzu ya da öğretmen verir. Öğretmen, yapılan deneyleri daha önce yapılmış olan çalışmalar ve deneylerle karşılaştırır ve öğrencilerin davranışlarına yön verir. Ortaya çıkan sonuçlar çoğunlukla umulan sonuçlarla karşılaştırılmaya çalışılır. Bu yaklaşım bu özelliği ile laboratuvar derslerinin, yemek tarifi gibi bir hususiyete bürünmesini sağlar. Böylece öğrenciler özgür düşünmeye ve deney esnasında yaptıkları ile ilgili tam bir anlam ilişkisi kurmaya gereksinim hissetmezler sadece ezbere yönelmiş olurlar (Kanl1, 2007). Ayrıca öğrencilerin belirtmiş oldukları ezbere dönük görüşlere bakıldığında, bireysel gelişimlerine bir şeyler katamayacakları için bu yaklaşımın öğrencilerde beceri geliştirmeyeceği ve becerikli olan öğrenciler için de konuyu sıkıcı hale getireceği şeklinde düşünceler laboratuvarlarla ilgili çalışmalarda yer almaktadır (Kayacan, 2014).

$\mathrm{Bu}$ çalışmada, istasyon tekniğine dayalı yapılan öğretimin Fen Bilgisi öğretmen adaylarının Fen Öğretimi Laboratuvar Uygulamaları II dersi başarısına etkisini incelemek amaçlanmıştır.

Araştırmanın problem cümlesi; "İstasyon tekniğine dayalı yapılan öğretimin Fen Bilgisi öğretmen adaylarının Fen Öğretimi Laboratuvar Uygulamaları II dersi başarısına etkisi var mıdır?” şeklindedir.

Araştırmanın problemi temel alınarak aşağıda verilen alt problemler oluşturulmuş ve bunlara cevap aranmıştır.

Birinci alt problem: İstasyon tekniği kullanılarak laboratuvar dersinin işlendiği deney grubu öğrencileri ile doğrulayıcı laboratuvar yaklaşımının kullanıldığı kontrol grubu öğrencilerinin başarı testi ön test puanları arasında anlamlı bir fark var mıdır?

İkinci alt problem: İstasyon tekniği kullanılarak laboratuvar dersinin işlendiği deney grubu öğrencilerinin başarı testi ön test puan ortalamaları ile son test puan ortalamaları arasında anlamlı bir fark var midır? 
Üçüncü alt problem: Doğrulayıcı laboratuvar yaklaşımı kullanılarak laboratuvar dersinin işlendiği kontrol grubu öğrencilerinin başarı testi ön test puan ortalamaları ile son test puan ortalamaları arasında anlamlı bir fark var mıdır?

Dördüncü alt problem: İstasyon tekniği kullanılarak laboratuvar dersinin ișlendiği deney grubu öğrencileri ile doğrulayıcı laboratuvar yaklaşımının kullanıldığı kontrol grubu öğrencilerinin başarı testi son test puanları arasında anlamlı fark var mıdır?

\section{Yöntem}

Araştırmalar nicel, nitel ve karma araştırma yaklaşımları olmak üzere 3 farklı türde ele alınabilmektedir. Bu çalışma nicel araştırma yaklaşımı kullanılarak yapılmıştır. Nicel araştırma yaklaşımı verilerin sayılarla sunulduğu görgül araştırmalardır (Punch, 2005). İstasyon tekniğine dayalı yapılan öğretimin Fen Bilgisi öğretmen adaylarının Fen Öğretimi Laboratuvar Uygulamaları II dersindeki başarısına etkisini incelemek amacıyla yapılan bu çalışmada nicel araştırma yaklaşımları arasından deneysel desen seçilmiştir. Deneysel desenler en sade anlamıyla değişkenler arasındaki neden-sonuç ilişkisini saptamaya yönelik yapılan araştırmalardır (Gay \& Airasian, 2000). $\mathrm{Bu}$ çalışma yarı deneysel desende yapılmıştır. Önceden oluşturulmuş sınıflardan biri deney grubu, diğeri kontrol grubu olarak belirlendiği ve öğrenciler arasında seçim yapılamadığ deseni kontrol gruplu "yarı deneysel desen" olarak belirlenmiştir. Biri deney ve diğeri de kontrol olmak üzere iki grup yansız atama yöntemiyle oluşturularak iki gruba da çalışma öncesi ve sonrası aynı test uygulanmıştır. Yarı deneysel desenli çalışmalarda iki gruba da ön ve son testler uygulanarak yalnızca deney grubuna yöntem uygulaması yapılır, kontrol grubu ise normal düzende devam eder (Creswell 2003).

\section{Örneklem}

Çalışmanın örneklemini; 2018-2019 eğitim-öğretim yılı bahar döneminde bir devlet Üniversitesinin Eğitim Fakültesi Fen Bilgisi Öğretmenliği Programı'nda öğrenim görmekte olan üçüncü sınıfta okuyan 58 öğrenci oluşturmaktadır. Çalışmada deney ve kontrol grupları oluşturulmuş ve deney grubunda araştırmacılar tarafından hazırlanan istasyon tekniği etkinlikleri kontrol grubunda ise doğrulayıcı laboratuvar yaklaşımına dayalı öğretim uygulanmıştır. Deney grubunda 28 öğrenci, kontrol grubunda ise 30 öğrenci bulunmaktadır.

\section{Uygulama Süreci}

İstasyon tekniğinin uygulandığ 1 deney grubunda, literatürde yer alan istasyon tekniğine dayalı öğretim etkinliklerinin örnekleri incelenmiştir. İstasyon tekniği etkinlikleri ve fen öğretimi alanında uzman 3 kişiden onay alınmış, esas uygulamadan 1 ay 10 gün önce 10 öğrencinin katılımı ile pilot uygulama yapılmıştır. Pilot uygulama sonucunda etkinlikler, etkinliklere verilen süreler, gerekli olan malzemeler yeniden düzenlenmiştir. Araştırmacılar tarafindan geliştirilen istasyon tekniğine dayalı öğretim ile ilgili etkinlikler ve hazırlanan etkinlik malzemeleri tamamlandıktan sonra esas uygulamaya başlanmıştır. Esas uygulama 8 hafta sürmüştür.

Esas uygulama için öğrenciler 4-5 kişilik gruplara ayrılmıştır. Her hafta, ders içeriklerine ve kazanımlara bağlı olarak araştırmacılar tarafindan oluşturulan etkinlikler istasyon tekniği kullanılarak sunulmuştur. Konu yoğunluğuna bağlı olarak her hafta 3 veya 4 tane istasyon oluşturulmuş ve her grubun bu istasyonlarda çalışma yapması, her istasyona katkıda bulunmaları sağlanmıştır. Araştırmacılar grupları gezmiş ve her gruba rehberlik etmiştir. Öğrenciler ile deneyden sonra tartışma ortamı oluşturulmuş, öğrencilere sorular sorulmuş ve öğrencilerin soruları yanıtlanmaya çalışılmıştır. Daha sonra öğrenciler elde ettikleri verileri raporlarına yazmıştır.

Kontrol grubunda, her hafta için yapılan etkinlikler deney kılavuzunda teferruatlı bir şekilde verilmiştir. Laboratuvar föyü önceki yıllarda yapılan etkinlerden yararlanılarak hazırlanmıştır. Bu yöntemde de öğrenciler etkinlikleri gerçekleştirirken, araştırmacılar 4-5 kişiden oluşan grupları 
gezmiş ve her gruba rehberlik etmiştir. Öğrenciler deneyden sonra elde ettikleri verileri raporlarına yazmıştır. Deney kılavuzunda deneyle ilgili teorik bilgi, deneyin nasıl yapılacağ olduğu da öğrencilere verilmektedir. Bu süreçte öğrenciler yanlızca kendilerine verilen görevleri yerine getirmektedir. Kontrol grubunda doğrulayıcı laboratuvar yaklaşımı ile yapılan etkinlikler 8 hafta sürmüştür.

\section{Veri Toplama Araçları}

Veri toplama aracı, Kırçiçek ve Yüksel (2018) tarafından geliştirilmiş olan Fen Öğretimi Laboratuvar Uygulamaları Başarı Testi (FÖLUBT) dir. FÖLUBT'nin güvenirlik Cronbach Alfa değeri için 0.77 değerine ulaşılmıştır. 0.7 ve üzeri değerlerin kabul edilebilir değer olduğu belirtilmektedir (Can, 2018). Testin geçerlik ve güvenirlik hesaplamaları istatistik alanında uzman kişi tarafından yapılmıştır. Öğrencilerin FÖLUBT sorularını tamamlama süresi ortalama 50 dakika olarak belirlenmiştir.

\section{Verilerin Toplanması}

Laboratuvar kullanımını kapsayan derslerle ilgili 2018-2019 Eğitim Öğretim yılında, üniversitelerin eğitim fakültelerinin Fen Bilgisi Öğretmenliği Anabilim Dalında üçüncü sınıflara başlayan programlardan önce Fen Öğretimi Laboratuvar Uygulamaları II dersi toplamda 4 saat olup, bu 4 saatin 2 saati teorik olarak, 2 saati ise uygulamalı olarak işlenmiştir. Dersin kapsamı kolay erişilebilen ve maliyeti düşük malzemelerle yapılan deneyleri, fizik, kimya ve biyolojiye dair basit malzeme ile yapılabilecek deneyleri, fizik, kimya ve biyoloji deneyleri; fen ve teknoloji programından yararlanılarak deney tasarlama, sınıfta sunum yapma gibi konuları içermektedir (Kırçiçek ve Yüksel, 2018). Laboratuvar uygulamalarında deney yapımı, deney tasarımı ve sunum yapma gibi konularda birçok teknikler kullanılmaktadır.

\section{Verilerin Analizi}

Yapılmış olan bu çalışmanın verilerinin analizi SPSS 22 paket programı kullanılarak yapılmıştır. Alt problemlere uygun olarak t-testleri yapılmıştır.

\section{Bulgular}

\section{Alt Problemlere Ait Bulgular}

Birinci alt problem: İstasyon tekniği kullanılarak laboratuvar dersinin işlendiği deney grubu öğrencileri ile doğrulayıcı laboratuvar yaklaşımının kullanıldığı kontrol grubu öğrencilerinin başarı testi ön test puanları arasında anlamlı bir fark var mıdır?

Tablo 1: Fen Laboratuvarı Başarı Testi Puanlarının Gruba Göre Bağımsız Örneklem tTesti Sonuçları

\begin{tabular}{lllllll}
\hline Grup & $\mathrm{N}$ & $\mathrm{X}$ & SS & Sd & t & $\mathrm{p}$ \\
\hline Deney & 28 & 6.86 & 2.55 & 56 & .46 & .65 \\
Kontrol & 30 & 7.27 & 4.05 & & & \\
\hline
\end{tabular}

İstasyon tekniği kullanılarak laboratuvar dersinin işlendiği deney grubu öğrencileri ile doğrulayıcı laboratuvar yaklaşımının kullanıldığı kontrol grubu öğrencilerinin başarı testi ön test puanlarının bağımsız örneklem t-testi sonuçları Tablo 1'de gösterilmiştir. İstasyon tekniği kullanılarak laboratuvar dersinin işlendiği deney grubu öğrencilerinin başarı testinden aldıkları puanların ortalaması $(X=6.86$; std. sapma $=2.55)$ doğrulayıcı laboratuvar yaklaşımının kullanıldığ 1 kontrol grubu öğrencilerinin başarı testinden aldıkları puanların ortalamasından $(X=7.27$; std. sapma $=4.05)$ düşüktür. Ortalamalar arasındaki fark anlamlı değildir, $\mathrm{t}(56)=.46 ; \mathrm{p}>.05$. İstasyon 
tekniği ile laboratuvar dersinin işlendiği öğrenciler ile doğrulayıcı laboratuvar yaklaşımının kullanıldığı öğrenciler özdeştir.

İkinci alt problem: İstasyon tekniği kullanılarak laboratuvar dersinin işlendiği deney grubu öğrencilerinin başarı testi ön test puan ortalamaları ile son test puan ortalamaları arasında anlamlı bir fark var midır?

Tablo 2: İstasyon Tekniği Kullanılarak Laboratuvar Dersinin İşlendiği Deney Grubu Öğrencilerinin Fen Laboratuvarı Başarı Testi Ön Test ve Son Test Puanlarının Bağımlı Örneklem tTesti Sonuçları

\begin{tabular}{|c|c|c|c|c|c|c|}
\hline Testler & $\mathrm{N}$ & $\bar{X}$ & SS & $\mathrm{Sd}$ & t & $\mathrm{p}$ \\
\hline Ön test & 28 & 6.86 & 2.55 & 27 & 16.31 & $.00 *$ \\
\hline Son test & 28 & 15.04 & 1.99 & & & \\
\hline
\end{tabular}

İstasyon tekniği kullanılarak laboratuvar dersinin işlenmesinin fen laboratuvarı başarısına etkisini incelemeye yönelik başarı testi puanlarının testlere göre bağımlı örneklemler t-testi sonuçları Tablo 2'de bulunmaktadır. İstasyon tekniği kullanılarak ders işlenildikten sonra öğrencilerin başarı testinden aldıkları puanların ortalaması $(\mathrm{X}=15.04$; std. sapma $=1.99)$ istasyon tekniği kullanılarak ders işlenilmeden önce öğrencilerin başarı testinden aldıkları puanlarının ortalamasından $(X=6.86$; std. sapma $=2.55$ ) yüksektir. Sonuçlara göre istasyon tekniği kullanılarak yapılan laboratuvar etkinlikleri öğrencide başarıyı anlamlı derecede yükseltmiştir $\mathrm{t}(27)=16.31 ; \mathrm{p}<.05$.

Üçüncü alt problem: Doğrulayıcı laboratuvar yaklaşımı kullanılarak laboratuvar dersinin işlendiği kontrol grubu öğrencilerinin başarı testi ön test puan ortalamaları ile son test puan ortalamaları arasında anlamlı bir fark var midır?

Tablo 3: Doğrulayıcı Laboratuvar Yaklaşımı Kullanılarak Laboratuvar Dersinin İşlendiği Kontrol Grubu Öğrencilerinin Başarı Testi Ön ve Son Test Ortalama Puanlarının t-Testi Sonuçları

\begin{tabular}{lllllll}
\hline Testler & $\mathrm{N}$ & $\mathrm{X}$ & $\mathrm{SS}$ & $\mathrm{Sd}$ & $\mathrm{t}$ & $\mathrm{p}$ \\
\hline Ön test & 30 & 7.27 & 4.05 & 29 & 7.56 & $.00^{*}$ \\
Son test & 30 & 12.60 & 2.13 & & & \\
\hline \multicolumn{2}{c}{${ }^{*} \mathrm{p}<.05$} & & & & &
\end{tabular}

Doğrulayıcı laboratuvar yaklaşımı kullanılarak laboratuvar dersinin işlenmesinin fen laboratuvarı başarısına etkisini incelemeye yönelik başarı testi puanlarının testlere göre bağımlı örneklem t-testi sonuçları Tablo 3'te gösterilmiştir. Doğrulayıcı laboratuvar yaklaşımı kullanılarak ders işlenildikten sonra öğrencilerin başarı testinden aldıkları puanların ortalaması $(X=12.60$; std. sapma=2.13) doğrulayıcı laboratuvar yaklaşımı kullanılarak ders işlenilmeden önce öğrencilerin başarı testinden aldıkları puanlarının ortalamasından $(X=7.27$; std.sapma $=4.05)$ yüksektir. Sonuçlara göre doğrulayıcı laboratuvar yaklaşımı kullanılarak yapılan laboratuvar etkinlikleri öğrencide başarıyı anlamlı derecede yükseltmiştir $\mathrm{t}(29)=7.56 ; \mathrm{p}<.05$.

Dördüncü alt problem: İstasyon tekniği kullanılarak laboratuvar dersinin işlendiği deney grubu öğrencileri ile doğrulayıcı laboratuvar yaklaşımının kullanıldığı kontrol grubu öğrencilerinin başarı testi son test puanları arasında anlamlı fark var midır? 
Tablo 4: Fen Laboratuvarı Başarı Testi Son Test Puanlarının Gruba Göre t-Testi Sonuçları

\begin{tabular}{lllllll}
\hline Grup & $\mathrm{N}$ & $\mathrm{X}$ & $\mathrm{SS}$ & $\mathrm{Sd}$ & $\mathrm{t}$ & $\mathrm{p}$ \\
\hline Deney & 28 & 15.04 & 1.99 & 56 & 4.49 & $.00^{*}$ \\
Kontrol & 30 & 12.60 & 2.13 & & & \\
\hline \multicolumn{2}{c}{${ }^{*} \mathrm{p}<.05$} & & & & &
\end{tabular}

İstasyon tekniği kullanılarak laboratuvar dersinin işlendiği deney grubu öğrencileri ile doğrulayıcı laboratuvar yaklaşımının kullanıldığı kontrol grubu öğrencilerinin son test puanlarının bağımsız örneklem t-testi sonuçları Tablo 4'te gösterilmiştir. İstasyon tekniği kullanılarak laboratuvar dersinin işlendiği deney grubu öğrencilerinin başarı testinden aldıkları puanlarının ortalaması $(X=15.04$; std. sapma=1.99), doğrulayıcı laboratuvar yaklaşımının kullanıldı grubu öğrencilerinin başarı testinden aldıkları puanların ortalamasından $(X=12.60$; std. sapma=2.13) yüksektir. Ortalamalar arasındaki anlamlı fark istasyon tekniği grubu $(\mathrm{t}(56)=4.49 ; \mathrm{p}<.05)$ lehinedir.

\section{Sonuç ve Tartıșma} ulaşılmıştır.

Çalışmada elde edilen veriler ve yapılan yorumlara dayanarak aşağıdaki sonuçlara

İstasyon tekniği kullanılarak laboratuvar dersinin işlendiği öğrencilerin fen laboratuvarı başarı ön testinden aldıkları puanlarının ortalaması, doğrulayıcı laboratuvar yaklaşımının kullanıldığı öğrencilerin başarı ön testinden aldıkları puanların ortalamaları arasındaki fark anlamlı değildir. $\mathrm{Bu}$ sonuca bakıldığında çalışma öncesinde deney ve kontrol gruplarının başarılarının aynı düzeyde olduğu söylenebilir.

İstasyon tekniği kullanılarak dersin işlendiği öğrencilerin fen laboratuvarı başarı testi ön ve son test ortalamalarına göre istasyon tekniği öğrencilerde fen laboratuvarı başarılarını anlamlı derecede yükseltmiştir.

Doğrulayıcı laboratuvar yaklaşımı kullanılarak dersin işlendiği öğrencilerin başarı testi ön test ile son test puan ortalamalarına göre doğrulayıcı laboratuvar yaklaşımı ile yapılan laboratuvar etkinlikleri öğrencilerde fen laboratuvarı başarılarını anlamlı derecede yükseltmiştir. Bunun sebebi doğrulayıcı laboratuvar yaklaşımınında çağdaş ve öğrenci merkezli bir yaklaşım olmasından kaynaklanmaktadır.

Son olarak istasyon tekniği kullanılarak laboratuvar dersinin işlendiği öğrencilerin fen laboratuvarı başarı testinden aldıkları son test puan ortalaması ile doğrulayıcı laboratuvar yaklaşımının kullanıldığı öğrencilerin başarı testinden aldıkları son test puan ortalamaları karşılaştırıldığında istasyon tekniği grubu lehine anlamlı bir fark ortaya çıkmıştır. Bu sonuçları yorumlayacak olursak istasyon tekniği ile öğrenim gören deney grubu öğrencilerininde, doğrulayıc1 laboratuvar yaklaşımı ile öğrenim gören kontrol grubu öğrencilerininde başarılarında artış meydana gelmiştir. Fakat bu artış istasyon tekniği ile öğrenim gören deney grubu öğrencilerinde daha fazladır.

Alanyazın taraması yapıldığında ulaşılan bu sonuçlara benzer sonuçların olduğu görülmüştür. Kara Ekemen (2017), yaptığı çalışmada ulaşılan verilere göre istasyon tekniğinin akademik başarı üzerine olumlu yönde etkilediği sonucuna ulaşmıştır. Aynı şekilde Korsacılar ve Çalışkan (2015); yaptıkları çalışmalarının sonucunda, istasyon tekniğinin kullanıldığı öğrencilerin başarı testi puanlarının iki gruba göre anlamlı düzeyde yüksek olduğunu belirlemişlerdir. Khishfe (2004), yaptığ 1 çalışmada öğrenme sürecinde öğrenciyi aktif hale getiren öğrenme istasyonları yönteminin düz anlatım yöntemine göre öğrencinin akademik başarısının arttırdığını belirtmiştir. Furutani (2007), araştırmasında istasyon tekniğinin öğrenci başarısını arttırdığını belirterek istasyon tekniğinin öğrenci ihtiyaçlarına göre beğenilen bir teknik olduğu sonucuna ulaşmıştır. Mergen (2011), 'İstasyon Tekniğinin İlköğretim 5. Sınıf Öğrencilerinin Akademik Başarılarına ve 
Öğrenmelerinin Kalıcılığına Etkisi’ isimli çalışmasında istasyon tekniğinin öğrencilerin başarısını artırdığını ve öğrenmelerinin kalıcılığını etkilediğini belirlemiştir. Yılmaz (2015), "9. Sınıf Öğrencileri İçin Kimyasal Türler Arası Etkileşimler Konusunda Öğrenme İstasyonlarının Geliştirilmesi ve Akademik Başarı Üzerindeki Etkisinin İncelenmesi” adlı araştırmasında istasyon tekniğinin öğrencilerin akademik başarısı, kavramsal anlamaları ve öğrenmelerinin kalıcılığına olumlu etki gösterdiğini belirtmiştir. Farkas (2002) çalışmasında istasyon tekniğinin öğrencilerin öğrenmelerinde etkili olduğunu ve öğrencilerin empati becerisini geliştirdiğini açıklamıştır. Porter (2004), istasyon tekniği ile yapılan dersin öğrencilerin matematik becerisini geliştirdiğini belirlemiştir. Demir (2008), istasyon tekniğinin hayat bilgisi dersindeki üst düzey bilgi erişisine etkisini araştırmış ve istasyon tekniğinde bulunan etkinliklerin öğrencilerde olumlu etkisi olduğu sonucuna ulaşmıştır. Güneş (2009), fen ve teknoloji dersinde istasyon tekniğinin öğrencilerin öğrenmeleri üzerine olumlu yönde etki ettiğini ve öğrenmelerin kalıc1lı̆̆ üzerine de etkisi olduğunu belirtmiştir. Maden ve Durukan (2010), 73 sekizinci sınıf öğrencisine istasyon tekniği uygulamıştır. İstasyon tekniğinin Türkçe dersinde öğrencilerin yaratıcı yazma becerilerini geliştirdiğini belirlemiştir. Benek (2012), fen ve teknoloji dersinde 7. sınıf öğrencilerine istasyon tekniğini uygulamış ve öğrencilerin öğrenmelerini olumlu yönde etkilediği gibi öğrencilerin tutumları üzerine de olumlu etki bıraktığını gözlemlemiştir. Sürücü, Özdemir, Baştürk (2013), istasyon tekniğini fen bilgisi öğretmen adayları için uygulamış ve öğretmen adaylarının kavram başarıları üzerine etkisinin olmadığını gözlemlemiştir. Kocamanoğlu (2014) yaptığı çalışmada okul öncesinde kullanılan istasyon tekniğini öğrencilerin yaratıcılı̆̆ etkisi olduğunu belirtmiştir. Avcı (2015), İngilizce dersinde istasyon tekniği kullanmış ve istasyon tekniğinin öğrencilerin akademik başarılarını olumlu yönde etkilediği sonucuna ulaşmıştır. Taşdemir (2015), sosyal bilgiler dersinde 6. sınıf öğrencilerine istasyon tekniği ile 'Ülkemizin Kaynakları' konusunun öğretilmesi ile ilgili çalışma yapmış ve istasyon tekniğinin öğrencilerin akademik başarısı üzerine etki ettiğini gözlemlemiştir.

Tüm sonuçlar değerlendirildiğinde istasyon tekniğinin öğrenci başarısının yükseltilmesinde etkili bir yöntem olduğu ortaya çıkmaktadır. Bu çalışma istasyon tekniğinin başarılı bir teknik olduğunu ortaya çıkarmaktadır. Şimdiye kadar istasyon tekniği ile ilgili yapılmış olan başarılı çalışmaları desteklemekte ve bundan sonra yapılacak olan çalışmalar için bir yol gösterici olmaktadir.

\section{Öneriler}

Bu çalışmada, kullanılan tekniklerin öğrencilerin başarılarını anlamlı derecede yükselttiği tespit edilmiştir. Bu sonuçlara göre aşağıdaki öneriler yapılabilir:

1. $\mathrm{Bu}$ araştırmadan elde edilen sonuçlar üniversite düzeyi ile sınırlıdır. Benzer çalışmalar ortaöğretim düzeyindeki öğrencilerle de gerçekleştirilebilir.

2. $\mathrm{Bu}$ araştırma 58 öğrenci ile gerçekleştirilmiştir. Farklı örneklemlerle araştırma genişletilebilir.

3. $\mathrm{Bu}$ araştırmada istasyon tekniği ile doğrulayıcı laboratuvar yaklaşımı karşılaştırılmştır. İstasyon tekniği ile farklı bir teknik, yaklaşım vb. karşılaştırılabilir.

4. $\mathrm{Bu}$ çalışmada, kullanılan tekniklerin öğrencilerin başarılarının yükselmesinde olumlu etkisinin olduğu tespit edilmiştir. Fen laboratuvarlarında öğretim sürecinin sistemli bir şekilde yürütülmesi ve öğretim programında yer alan konuların öğretilmesi açısından laboratuvar derslerinde istasyon tekniğine daha çok yer verilmelidir. 


\section{Kaynakça}

Aktamış, H. ve Ergin, Ö., (2007). Bilimsel Süreç Becerileri İle Bilimsel Yaratıcılık Arasındaki İlişkinin Belirlenmesi. Hacettepe Üniversitesi Eğitim Fakültesi Dergisi 33, 11-23.

Avcı, H. (2015). Ingilizce öğretiminde istasyon tekniği kullanımının akademik başarıya, tutumlara ve kalıcllı̆ga etkisi. Yüksek Lisans Tezi. Fırat Üniversitesi Eğitim Bilimleri Enstitüsü.

Benek, İ. (2012). İstasyonlarda öğrenme tekniğinin ilköğretim 7. sinıf ögrencilerinin fen ve teknoloji dersindeki başarılarına etkisi. Yüksek Lisans Tezi, Yüzüncü Yıl Üniversitesi Fen Bilimleri Enstitüsü.

Can A. (2018). SPSS ile bilimsel araştırma sürecinde nicel veri analizi. (6. bask1). Pegema Yayınc1l1k. ISBN: 6053644484

Creswell, J.W. (2003). Research design. Sage Publication.

Çepni, S. ve Ayvacı, H.Ş. (2006). Kuramdan uygulamaya fen ve teknoloji öğretimi. (5. baskı). Pegema Yayıncilik.

Demir, M. R. (2008). İstasyonlarda öğrenme modelinin hayat bilgisi dersindeki üst düzey beceri erişisine etkisi. Yüksek Lisans Tezi, Hacettepe Üniversitesi.

Farkas, R. D. (2002). Effect(s) of traditional versus learning styles instructional methods on seventh grade students achievement, attitudes, empathy and transfer skills through a study of the holoaust. Doctoral Dissertation, St. John's University.

Furutani, S. S. (2007). How does one successfully implement learning centers the third grade level?. Master's Thesis, Pacific Lutheran University.

Gay, L. R. \& Airasian, P. (2000). Educational research competencies for analysis and application (6th Edition). Merrill an imprint of Prentice Hall.

Güneş, E. (2009). Fen ve teknoloji dersinde istasyon tekniği ile yapılan öğretimin erişiye ve kalıcılı̆̆a etkisi. Yüksek Lisans Tezi, Hacettepe Üniversitesi.

Hofstein, A. \& Lunetta,V. N., 2004. The Laboratory in Science Education: Foundations for the Twenty-First Century. Science Education, 88, 28 - 54.

Kanlı, U. (2007). $7 E$ modeli merkezli laboratuvar yaklaşımı ile doğrulama laboratuvar yaklaşımlarının ögrencilerin bilimsel süreç becerilerinin gelişimine ve kavramsal başarılarına etkisi. Doktora Tezi, Gazi Üniversitesi.

Kara Ekemen, D. (2017). Biyolojik çeşitlilik ve korunması konusunun öğretilmesinde istasyon tekniği kullanımının 9. sınıf ögrencilerinin akademik başarıları ve tutumları üzerine etkisi. Yüksek lisans tezi, Gazi Üniversitesi.

Kayacan K. (2014). Özdüzenleme faaliyetleri ile zenginleştirilmiş araştırma-sorgulamaya dayalı ögretim stratejisinin fen bilgisi ögretmen adaylarının kuvvet ve hareket konusunu kavramsal anlamalarına ve akademik özyeterliklerine etkisi. Doktora tezi, Gazi Üniversitesi.

Khishfe, R. F. (2004). Relationship between students' understanding of science and instructional context. Doctoral Dissertation, Illinois Institute of Technology.

Kırçiçek H. ve Yüksel İ. (2018). Fen bilgisi öğretmen adayları için fen öğretimi laboratuvar uygulamaları başarı testinin geliştirilmesi (pilot uygulama), öğrencilerin bekledikleri notlarla aldıkları notlar arasındaki ilişki ve yeni programdaki laboratuvar uygulamaları hakkındaki görüşleri. Ĕgitim Bilimlerinde Güncel Akademik Çalışmalar-2018. Ivpe Cetinje, Montenegro. ISBN: 978-9940-540-47-0 
Kocamanoğlu, D. Ö. (2014). Öğrenme merkezleri kullanılarak oluşturulan bir okul öncesi eğitim sinıfinda çocukların sanat ürünlerinin incelenmesi ve estetik yargilarının belirlenmesi. Yüksek Lisans Tezi, Ankara Üniversitesi Eğitim Bilimleri Enstitüsü.

Korsacılar, S., ve Çalışkan, S. (2015). Yaşam temelli öğretim ve öğrenme istasyonları yönteminin 9. sınıf fizik ders başarısı ve kalıcılığa etkileri. Mersin Üniversitesi Ĕgitim Fakültesi Dergisi, 11(2), 385-403.

Maden, E., \& Durukan, S. (2010). İstasyon tekniğinin yaratıcı yazma becerisi kazandırmaya ve derse karş1 etkisi. Türk Bilimi Araştırmaları, 28(28), 299-312.

Mergen, H. H. (2011). Illköğretim 5. sinlf sosyal bilgiler dersinde ögrenme istasyonlart uygulamasının akademik başarıya ve kalıcılığa etkisi. Yüksek Lisans Tezi, Afyon Kocatepe Üniversitesi.

Ocak, G. (Ed. ). (2017). Öğretim ilke ve yöntemleri (10. Bask1). Pegem Akademi Yayınları.

Porter, E. J. (2004). Classroom learning centers: study of a junior high school learning assisted program in mathematics. Master's Thesis, Pacific Lutheran University.

Punch, K. F. (2005). Sosyal Araştırmalara Giriş (H. Bayrak \& Z. Akyüz, Çev.). Siyasal.

Sürücü, A., Özdemir, H., \& Baştürk, R. (2013). Fen bilgisi öğretmen adaylarının kavram başarılarına istasyonlarda öğrenme modelinin etkisi. Elektronik Sosyal Bilimler Dergisi, 12(45), 52-62.

Taşdemir, D. (2015). Sosyal bilgiler dersi 6. sınıf 'ülkemizin kaynakları' ünitesinin istasyon tekniği ile öğretiminin ögrencilerin akademik başarılarına ve derse karşı tutumlarına etkisi. Yüksek Lisans Tezi, Fırat Üniversitesi Eğitim Bilimleri Enstitüsü.

Yıldız, M. (2012). Geometrik optik ögretiminde yapılandırmacı ögrenme kuramına dayalı olarak geliştirilen laboratuvar materyallerinin etkililiğinin değerlendirilmesi. Yüksek lisans tezi, Karadeniz Teknik Üniversitesi, Eğitim Bilimleri Enstitüsü.

Yılmaz, G. (2015). 9. sinıf ögrrencileri için kimyasal türler arası etkileşimler konusunda ögrrenme istasyonlarının geliştirilmesi ve akademik başarı üzerindeki etkisinin araştırılması. Yüksek Lisans Tezi, Dokuz Eylül Üniversitesi.

Zentall, S. S., \& Zantall, T. R. (1976). Activity and task performance of hyperactive children as a function of environmental simulation. Journal of Consulting and Clinical Psychology, 44(5), 693-697. 